\title{
Power Market Operation Efficiency Evaluation Based on a Hybrid BP Neural Network: A perspective from Market Regulator in China
}

\author{
Jun Dong, Yao Liu*, Zhenjie Chen, Yaoyu Zhang, Yuzheng Jiang \\ School of Economics and Management, North China Electric Power University, Beijing, China \\ Email address: \\ dongjun@ncepu.edu.cn (Jun Dong), 120192206101@ncepu.edu.cn (Yao Liu), 120202206267@ncepu.edu.cn (Zhenjie Chen), \\ 120192206012@ncepu.edu.cn (Yaoyu Zhang),120202206107@ncepu.edu.cn (Yuzheng Jiang) \\ ${ }^{*}$ Corresponding author
}

\section{To cite this article:}

Jun Dong, Yao Liu, Zhenjie Chen, Yaoyu Zhang, Yuzheng Jiang. Power Market Operation Efficiency Evaluation Based on a Hybrid BP Neural Network: A perspective from Market Regulator in China. American Journal of Electrical Power and Energy Systems.

Vol. 10, No. 5, 2021, pp. 82-99. doi: 10.11648/j.epes.20211005.12

Received: October 30, 2021; Accepted: November 16, 2021; Published: November 23, 2021

\begin{abstract}
The electricity market reform in China promotes the marketization process of the electricity market, but in this process, there are still some behaviors that disturb the market order. The operation of electricity market needs to be evaluated in order to evaluate its operation efficiency, and the regulatory agency is an important part of it, so it is very necessary to construct the evaluation index and method of the operation efficiency of electricity market from the perspective of the regulatory agency. This paper constructed an evaluation system of power market operation efficiency based on hybrid BP neural network. In the construction of methods, appropriate evaluation methods become very necessary when considering the uncertainty and ambiguity of the assessed things. Based on the above analysis, this paper constructed an evaluation index system of power market operation efficiency based on SCP model, and constructed evaluation methods based on fuzzy Delphi, fuzzy AHP and neural network. Finally, this paper selects the actual data of a certain region for example verification, and conducts sensitivity analysis to analyze the factors that have a key impact on the efficiency of market operation, and draws the conclusion of this paper. This paper hopes that the research results can be applied to the decision-making of regulators in order to make the electricity market run efficiently.
\end{abstract}

Keywords: Power Market Monitoring, SCP Model, Fuzzy Set, BP Neural Network, Multi-criteria Decision Making

\section{Introduction}

\subsection{Background}

In 2015 , the issuance of power industry reform document NO. 9 marked the beginning of a new round of China's electric power industry reform. The purpose of the new round of electricity reform is to break the market monopoly, introduce competition mechanism, and then improve the efficiency of market operation [1]. In recent years, China's electric power market reform has been accelerated and achieved positive results, but on the whole, There are still problems in the operation of electricity market to different degrees. The division of market supervision is not clear, the independence of regulatory agencies is poor, the supervision of power monopoly enterprises is not in place, the existence of market power hinders market supervision, and the lack of market supervision further aggravates the exercise of market power by power producers, which is not conducive to the improvement of the operation efficiency of power market. Generally speaking, the construction of power market system needs to be improved, and the order of market operation needs to be further standardized.

Power market is a complex economic system, in which the behavior of each market participant can affect others, and all market behaviors may trigger repercussions in the later market [2]. Meanwhile, the results of power transaction affect the operation of power system. The stable operation of power market directly affects the security and stability of power system. Therefore, it is necessary to monitor whether there is 
any behavior that affects the operation of the electric power market, so as to avoid the market behavior affecting the safe and stable operation of the whole system. As the basic pillar industry of national economy, the operation efficiency of electric power industry is of great significance to the effective operation of the whole society. In 2015, the National Energy Administration in the electric power market regulation (draft) is put forward, the energy regulator, the local government administrative departments of electric power shall establish a monitoring mechanism for the operation of the power market to monitor and evaluate the operation of the power market, so as to detect and avoid the abuse of market power and market manipulation, improve the operation efficiency of the power wholesale market and maintain the order of fair competition in the market [3]. The purpose of power market reform is to improve the efficiency of the market. Whether this goal is achieved needs to use a set of monitoring indicators and evaluation system to analyze and evaluate, and then effectively evaluate the operation of the power market, so as to achieve the purpose of improving the efficiency of the power market.

This paper analyzes the indicators of monitoring the operation efficiency of the electricity market and builds an evaluation model to evaluate the current operation status of the electricity market. Moreover, the factors affecting the operation efficiency of the electricity market can be effectively monitored, so as to improve the operation efficiency of the electricity market. At the same time, according to the existing research results worldwide, a comprehensive power market monitoring index system is obtained based on the current situation of the power market, which provides a reference for energy regulatory agencies and local governments to design regulatory schemes.

\subsection{Literature Review}

As the electric power is the pillar industry related to the national economy and people's livelihood, electric power has always been the focus of scholars. At present, abundant research achievements have emerged in the field of electric power industry evaluation, mainly focusing on the evaluation of power system and the evaluation of power market. The evaluation of power system mainly includes reliability evaluation [4], power quality evaluation [5] and the effect of energy saving and emission reduction [6]. Electricity market evaluation mostly focuses on electricity price mechanism evaluation [7], market power evaluation [8], credit risk evaluation of power enterprises [9] and performance evaluation of power enterprises [10], However, there are few papers on the evaluation of monitoring results of power market operation from the perspective of regulators. Power market operation monitoring is an important part of the power market, and it is a key indicator to master the market operation dynamics and operation risks, so it is very necessary to evaluate it.

The evaluation of power market operation monitoring needs a suitable index system and evaluation method. In the aspect of index system construction, most studies are guided by the overall goal of power market construction, and construct corresponding index system from the two major goals of safe and reliable operation and economic and efficient operation [11]. Some literature construct the index system from the transaction characteristics of electricity market [12]. Literature [12] constructs an evaluation index system of electricity market transaction from the perspective of transaction situation, including the fundamentals of electricity industry, market setting and actual transaction. However, the power market operation index system is related to each other, and the construction of the index system needs to be complete, scientific and reasonable [13]. Compared with the traditional method of index system construction, SCP model is currently widely used as an analysis paradigm [14]. It believes that there is a causal relationship between structure, behavior and performance, which can avoid the singleness of index system construction [15].

In terms of evaluation methods, traditional evaluation methods are widely used, but they also have many limitations, such as the low accuracy of expert scoring method, and the high sensitivity of entropy weight method, which may easily lead to index failure. Due to the simultaneous occurrence of production, transportation and consumption of electric power commodities, most scholars choose the uncertainty evaluation method [16] in the evaluation of the electric power field. Compared with the shortcomings of traditional evaluation methods, fuzzy theory and intelligent algorithm can solve this defect. In terms of index screening and weight determination, fuzzy Delphi method and fuzzy AHP method are proposed, among which the fuzzy Delphi method solves the screening problem of index values that are difficult to define [17]. Secondly, analytic hierarchy Process (AHP) determines the weight of indicators for evaluation, which can realize the hierarchical and orderly treatment of complex problems. Fuzzy AHP can describe the evaluation objects more accurately based on the combination of qualitative and quantitative methods. In terms of evaluation methods, BP neural network algorithm has been applied in a large number of studies. BP neural network is characterized by strong mapping ability and outstanding self-adaptation ability [18]. The fuzziness and randomness of artificially determined weights can be overcome by combining various methods [19]. Compared with the traditional evaluation method, it is more conducive to solving the uncertain problem of evaluation of market operation monitoring.

\subsection{Innovation Point}

In order to fill the research gap, this paper systematically proposes a set of evaluation index system that is suitable for power market operation monitoring. Besides, a hybrid model considering uncertainty and fuzziness is proposed based on SCP technique, fuzzy set theory and BP neural network algorithm. The main contributions of this paper are as follows:

(1) Construct the power market operation monitoring index system based on SCP model. Different from the traditional research on the construction of economic, environmental and social macro dimensions of the 
index system, this paper adopts the SCP model to build the index system with "market structure, market behavior, market performance" as the standard, which is more consistent with the actual operation of the electricity market. At the same time, it can also better measure the behavior order of the electricity market operation monitoring.

(2) Fuzzy set theory is used to consider the fuzziness and uncertainty in the evaluation process. In this paper, fuzzy Delphi is used to preliminarily screen the index system constructed by experts, and fuzzy AHP is used to construct the weight of the index system. Meanwhile, fuzzy operator is used to get the evaluation results of each training set and test set, which fully considers the fuzziness of experts in evaluation and makes the results closer to the real value.

(3) Artificial intelligence algorithm-BP neural network is used for evaluation. BP-ANN is a simple and reliable neural network, which has been widely used in many fields because of its excellent self-learning ability. In this paper, intelligent algorithm is applied to evaluate the operation monitoring of power market, which is more realistic and interactive.

The other chapters of this paper are arranged as follows: The second section constructs the index system of electricity market operation monitoring; The third section introduces the research methods used in this paper. In the fourth and fifth sections, examples are given to verify and discuss. The sixth section gives the conclusion of this paper. The technical roadmap for this article is as shown in figure 1.

\section{Evaluation of power market operation monitoring}

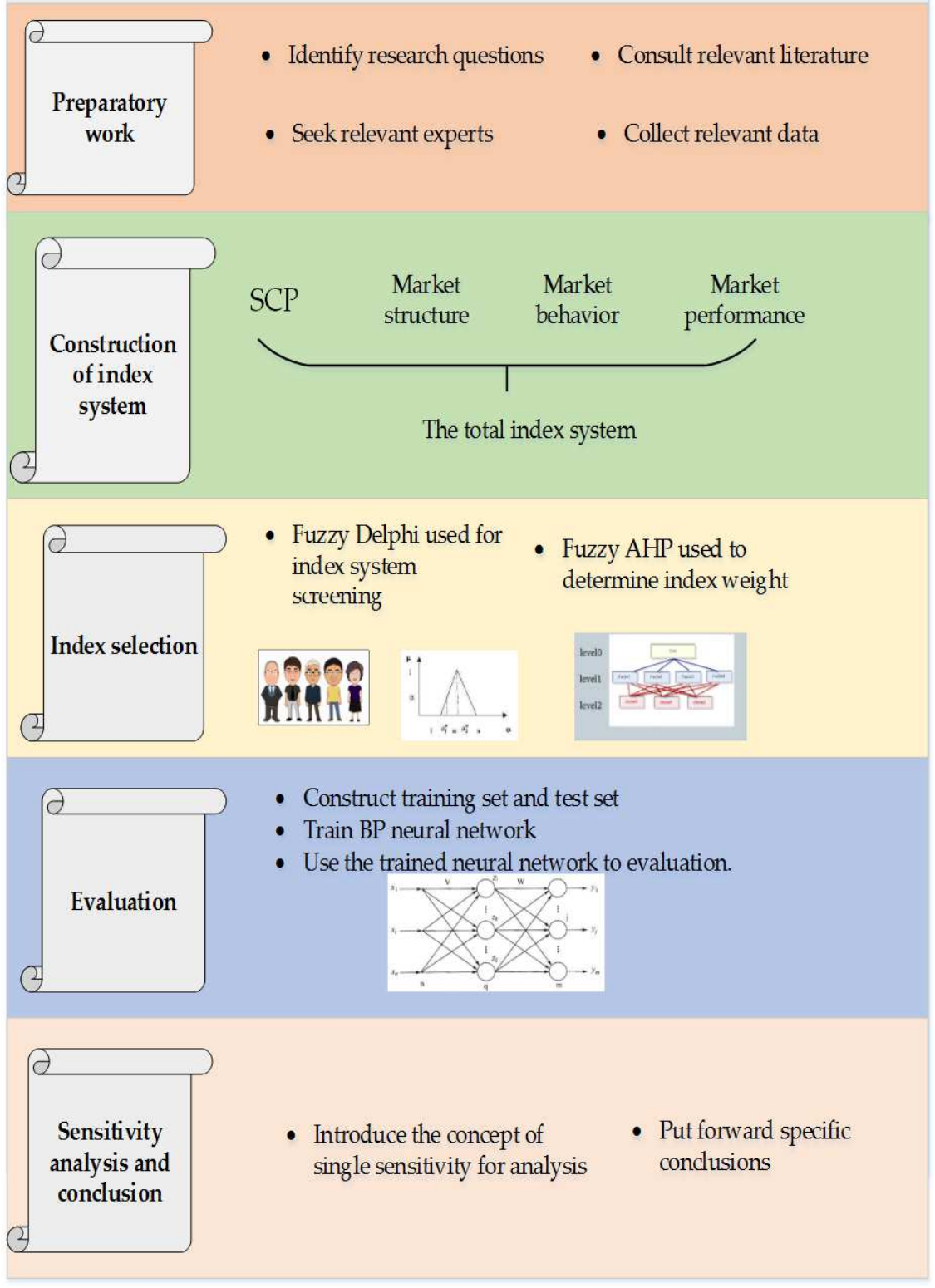

Figure 1. The technology roadmap. 


\section{Construction of the Evaluation Index System}

\subsection{Construction Principle and Content of Index System}

Electricity market monitoring is a necessary step to realize efficient and stable operation of power market. The purpose of electricity market monitoring is to monitor market behavior and realize the effective competition of electricity market. When constructing the monitoring index system of electricity market operation efficiency, we can start from the monitoring purpose of electricity market, that is, to realize the effective competition of electricity market, and combine the existing research results and the successful monitoring index system of electricity market to analyze.

Clark, an American economist, defines effective competition as a competitive pattern that gives full play to economies of scale. On this basis, Mason defined effective competition as promoting economic growth and technological progress, and judged whether the market was effective from two aspects of market structure and performance. Referring to previous theories, Bain has completely proposed the basic research paradigm of modern industrial organization theory: market structure, market behavior, market performance, referred to as SCP analysis paradigm [20]. It can be concluded from the PJM third-party monitoring report that the monitoring indicators of PJM power market are given from the four aspects of market structure, market behavior, market performance and shortage, and on this basis, the next level indicators are given. Therefore, in the construction of the power market operation monitoring index system, we can use SCP model for reference, analyze the market structure, market behavior, market performance, combined with existing literature research, to build a specific index system.

(1) Market structure index system

The market structure measures the overall situation of the electric power industry and the degree of competition within the industry, and measures the market power, reflecting the market competition relationship. The market structure is mainly measured by the following factors:

1) B1: Elasticity of market supply

$$
\text { Elasticity of market supply }=\frac{\text { Change in supply }}{\text { Change in price }},
$$

2) B2: Elasticity of market demand

Elasticity of market demand $=\frac{\text { Change in demand }}{\text { Change in price }}$,

3) B3: Market report electricity supply/demand ratio

$$
\text { Market report electricity supply/demand ratio }=\frac{\text { Total market supply declared quantity }}{\text { Total market demand declared quantity }}
$$

The ratio of electricity supply and demand declared by the market is measured by the ratio of the total amount of electricity declared by the power generation company to the total amount of electricity demanded by the power buyer, which reflects the monopoly power of the power generation company in the electricity market. When the market supply/demand ratio tends to 1 or less than 1 , the market is in short supply, and the power producer can monopolize the market and manipulate the market price. On the contrary, the market is highly competitive.

4) B4: Market shares

Market share is the sum of the percentage of sales held by the $\mathrm{n}$ largest companies in the relevant market. When an enterprise's market share exceeds a certain standard (such as $20 \%$ in the United States), it is considered to have market power.

5) B5: Herfindahl-Hirschman Index (HHI)

$$
H H I=\sum_{i=1}^{N}\left(\frac{X_{i}}{X} \times 100\right)^{2}=\sum_{i=1}^{N}\left(S_{i} \times 100\right)^{2},
$$

Where, $\mathrm{X}$ is the total market size, $\mathrm{Xi}$ is the scale of enterprise $\mathrm{i}, \mathrm{Si}$ is the market share of the ith enterprise, and $\mathrm{n}$ is the number of enterprises in the electric power industry. The size of HHI index depends on the number of power generation enterprises in the market and the unequal market share of each power generation enterprise. When $\mathrm{HHI}<1000$, the market concentration is low and the competition is good. When $1000<\mathrm{HHI}<1800$, the market concentration is moderate;
When $\mathrm{HHI}>1800$, the market concentration is high.

6) B6: The entropy coefficient

Entropy coefficient borrows the concept of entropy in information theory and has the meaning of average amount of information. Its definition formula is as follows:

$$
E I=\sum_{i=1}^{N} S_{i} \log \left(1 / S_{i}\right),
$$

Where, EI is the entropy index; $\mathrm{Si}$ is the market share (sales volume or added value, etc.) of enterprise $i$; $n$ is the total number of enterprises in the market. The larger the EI value, the smaller the market concentration, the smaller the EI value, the greater the market concentration.

7) B7: Top-m

Top- $\mathrm{m}$ index is defined as the sum of the market shares of $\mathrm{m}$ power generation enterprises with the largest market share.

$$
\text { Top }-m=\sum_{i=1}^{m} S_{i}
$$

Where $S_{i}$ is the market share of the ith power generation enterprise in order of market share from large to small. For a particular $\mathrm{m}$, the larger the Top- $\mathrm{m}$ index is, the higher the concentration of the market is. In the industrial field, $m=4$ is generally taken. When the top- 4 index is greater than 65 , it indicates that the market has the nature of oligopoly.

8) B8: Concentration Ratio $\left(C R_{n}\right)$

$$
C R_{n}=\sum_{i=1}^{m} S_{i},
$$

The index refers to the sum of the market share of the top $n$ 
largest power generation companies in the selected region, which is an important quantitative index of market power. In the formula, $\mathrm{n}$ refers to the ranking number of market share, that is, the industry concentration of the top $n$ enterprises with the largest scale. In $\mathrm{CR}_{\mathrm{n}}$ studies, $\mathrm{n}$ equals 4 and 8 are usually selected for evaluation. Generally, if $\mathrm{CR}_{4}$ is greater than $30 \%$, the market can be regarded as oligarchic rather than competitive. The higher the market concentration rate is, the stronger the possibility that the market tends to be monopolistic and the lower the market efficiency is.

9) B9: Residual supply index $\left(\mathrm{I}_{R S I}\right)$

$$
\mathrm{I}_{R S I}=\frac{\sum_{i=1}^{N} q_{i}}{D}-\frac{q_{i}}{D},
$$

Where, $\mathrm{q}_{\mathrm{i}}$ is the declared electric quantity of each supplier, $\mathrm{N}$ is the number of suppliers, $\mathrm{D}$ is the total electric quantity demanded by the market, and $\mathrm{I}_{R S I}$ is the surplus supply rate of the i-th supplier. If $\mathrm{I}_{R S I}>1$, the market supplier does not have market power, on the contrary, the supplier has the ability to monopolize the market.

10) B10: Pivotal supplier indicators

$$
\begin{array}{r}
\text { PSI }= \\
\text { Total market demand - } \\
\text { total declared electricity of the market }+ \\
\text { total declared electricity of the target group, }
\end{array}
$$

The indicator evaluates whether a single supplier is capable of taking on all the remaining capacity of the market, i.e. fully influencing the transaction price by its own market share. In theory, key suppliers have the ability to set the final transaction price under the uniform clearing system. If the result is positive, the target group is the key supplier.

(2) Market behavior index system

Market behavior refers to the corresponding behaviors taken by enterprise participants according to the market environment. In the electric power market, the measurement of market behavior mainly starts from the behavior of suppliers, studies the behavior of individual suppliers that may have market dominance, analyzes the behavior of suppliers' quotation, and the corresponding strategy of declaring electric quantity, and analyzes whether suppliers control the market through electricity price and declared electric quantity.

1) B11: The highest declared price

This index refers to the highest price declared by power generation companies in the market. If the price exceeds a certain limit, it will disrupt the market order to some extent.

2) B12: The lowest price declared

This index refers to the lowest price declared by power generation companies in the market. If the price exceeds a certain limit, it will disrupt the market order to some extent.

3) B13: Declaration of marginal price difference between supply and demand

This indicator reflects the difference in market estimates between buyers and sellers. The greater the difference, the more competitive the market will be, and the more incentive power generation companies will have to reduce costs and offer prices, thus improving market efficiency.

\section{4) B12: Clearing price}

The monitoring of the clearing price mainly analyzes its stability. The relatively stable electricity price level reflects the effectiveness of the market to some extent. Excessively low quotation and excessively high price are maliciously disturbing the market order, which is not conducive to the long-term and orderly development of the electricity market.

5) B13: The amount of electricity declared by the power generation company

The interests of market subjects are directly related to the transaction quantity of electricity. By monitoring the declared quantity of electricity in each transaction of power generation companies, we can analyze whether power generation companies use electricity to influence the transaction price. Different regions have different regulations on the declared electric quantity of power generation companies. In some regions, the declared electric quantity should not be lower than a certain proportion of the total transaction electric quantity, and the specific standard should be determined according to specific regions.

6) B14: The electricity turnover rate declared by the power generation company

On the basis of monitoring the declared electricity quantity, the transaction electricity quantity is monitored at the same time, the transaction rate of the declared electricity quantity of the power generation company is calculated, the situation of unsold electricity quantity is analyzed, and then the behavior of each power generation subject is analyzed, and the behavior of whether there is more unsold electricity quantity of the main power generation subject affects the transaction price is analyzed.

\section{7) B17: Production gap factor}

The production gap is defined as the difference between the amount of capacity a generator brings to market and makes money and its actual capacity. If the production gap coefficient is too large, it can indicate the existence of physical or economic retention of power producers, and thus drive up power prices, which is one of the manifestations of abuse of market power. Production gap coefficient is the most commonly used index for economic retention detection. By comparing the historical average output level of a generator set, the paper analyzes whether it has abnormal output decline or other behaviors, so as to determine whether to use market power.

8) B18: Declarative conservative behavior

This behavior is mainly measured by the declared capacity participation index, which is the ratio of the actual declared capacity to the supplier's generating capacity.

(3) Market performance index system

Market performance reflects the efficiency of market operation and refers to the realistic state that market economic benefits can be achieved through certain market behaviors under a certain market structure. Through performance evaluation, check and improve the economic efficiency of the market, and judge whether the market price is effective and reasonable.

1) B19: Transaction surplus

Transaction surplus refers to the sum of consumer surplus 
and producer surplus, which can measure the economic welfare of the society. Consumer surplus refers to the interests gained by the electricity seller in the buying and selling activities, while producer surplus refers to the interests gained by the power generation company in the transaction. Transaction surplus refers to the social benefits of the market. The larger the transaction surplus is, the higher the market efficiency is.

$$
\begin{gathered}
\text { Transaction surplus }=\text { producer surplus }+ \text { consumer surplus } \\
\text { Producer surplus }=(\text { average clearing price }- \text { average seller's offer }) \times \text { volume } \\
\text { Consumer surplus }=(\text { average buyer price }- \text { average clearing price }) \times \text { volume }
\end{gathered}
$$

2) B20: Producer surplus ratio

Producer surplus ratio is the ratio of producer surplus to trade surplus. If the market is in an efficient and stable state, then the producer surplus ratio should be in a relatively stable state. If there are behaviors that disturb the market order, the price fluctuation will reduce consumer surplus and increase the proportion of producer surplus.

$$
\text { Producer surplus ratio }=\frac{\text { Producer surplus }}{\text { Transaction surplus }}
$$

3) B21: Lerner Index

$$
L=\frac{P-M C}{P},
$$

Where $\mathrm{P}$ is the price, $\mathrm{MC}$ is the marginal cost, and $\mathrm{L}$ is the Lenard index, which varies from 0 to 1 . The larger the Lerner index is, the greater the monopoly power is.

4) B22: Total efficiency of market operation (ME)

$$
M E=\frac{M C}{P},
$$

Where, $\mathrm{MC}$ is the marginal cost and $\mathrm{P}$ is the transaction price. The smaller the value, the greater the price deviates from the cost and the worse the market efficiency. The larger the value, the better the market competition state and the higher the efficiency.

5) B23: Rate of price increase

$$
\text { Rate of price increase }=\frac{\text { Reporting period price }- \text { Base period price }}{\text { Base period price }}
$$

6) B24: Market competition index

This index refers to the accumulation degree and competition status of competitors in the same space region, which will have an impact on the price of the product, which is determined by the demand state of the whole market and the cost of the product.

\subsection{Index System}

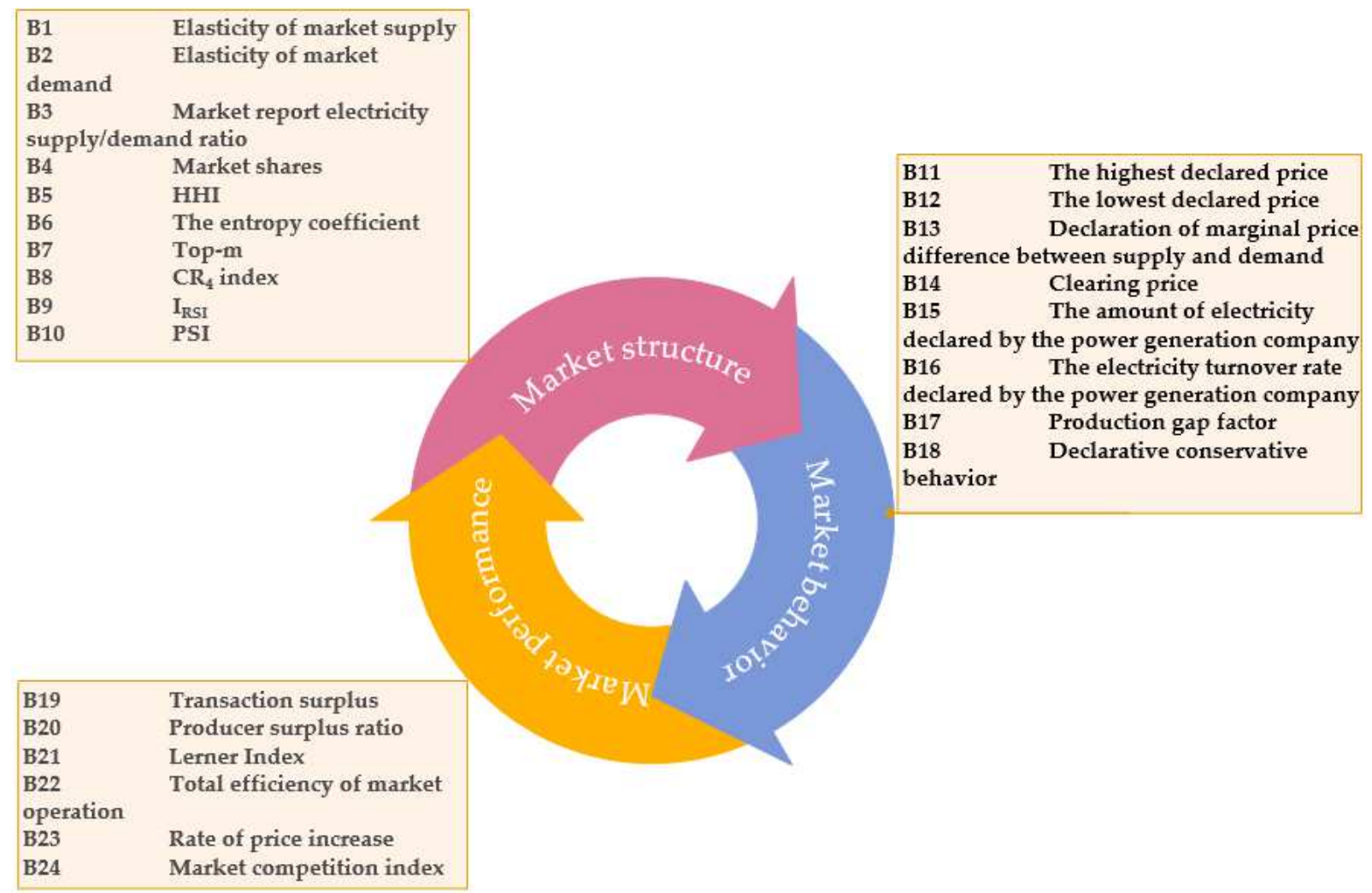

Figure 2. The total index system. 
Based on the index content analyzed in Section 2.1, the overall index structure can be obtained as shown in the figure 2. The power market operation monitoring index system generally contains three-level indicators, namely, market structure (A1), market behavior (A2) and market performance (A3), and different second-level indicators are contained under each first-level indicator.

\section{Methodology}

\subsection{Fuzzy Logic}

According to the traditional set theory viewpoint, extracting element $\mathrm{X}$ from domain $\mathrm{X}$ for theoretical analysis, it can be known that there will be relations between $X$ wholly belonging to A or $\mathrm{X}$ wholly not belonging to A, respectively recorded as $x \in A$ or $x \notin A$, the above relations can be described as follows by mathematical method:

$$
\mu_{A}(x)=\left\{\begin{array}{l}
1, x \in A \\
0, x \notin A
\end{array},\right.
$$

For element $\mathrm{x} \in \mathrm{A}$, there is a specific $\mu_{A}(x) \in\{0,1\}$ corresponding to it. The mapping form can be described by the following expression:

$$
\mu_{A}(x): X \rightarrow\{0,1\}
$$

Such a set is also called a hard set when the relationship between elements is clear. However, according to experience, the boundary of many objects is not clear, showing certain fuzzy characteristics. This fuzzy attribution relationship affects the judgment and analysis of things. In the 1960s, Zadeh introduced the concept of "Fuzzy" and analyzed it concretely from the perspective of probability theory. Zadeh extended the value range of the function $\mu_{A}(x)$ corresponding to equation (17) from $\{0,1\}$ to the real number field $[0,1]$, so that it could efficiently analyze the attribute division of some things with fuzzy attribution.

The corresponding mathematical definition of fuzzy set is as follows: The fuzzy set on domain $X$ is denoted as $\bar{A}$, and the related function $\mu_{\bar{A}}(x)$ is called membership function. If the corresponding function is larger, the element $\mathrm{x}$ is more likely to be in set $\bar{A}$. Therefore, for any element $x \in X$, the membership function related to this is also determined as

$$
\mu_{\bar{A}}(x): X \rightarrow[0,1], \mu_{\bar{A}}(\mathrm{x}): X \rightarrow[0,1],
$$

In fuzzy set theory, there are various numerical forms to describe fuzzy information, but sometimes due to the particularity of the decision problem and the complexity of the decision information, the final decision result may be less scientific and accurate. Fuzzy number plays an important role in fuzzy multi-criteria decision making. If some problems are difficult to be expressed by exact numbers, fuzzy numbers can be used to describe them. Triangle fuzzy number is one of the important ones. Triangular fuzzy numbers can effectively represent the information that is difficult to be described by precise numerical values, and can also be converted flexibly with other fuzzy numbers, so as to solve the problems in many fields, so it has been widely studied by many experts and scholars [21].

In domain $\mathrm{A}$, the representation of triangular fuzzy number is: $\mathrm{S}=\left(l_{1}, x^{M}, x^{U}\right)$, where, $x^{L} \leq x^{M} \leq x^{U}$. $x^{L}, x^{M}, x^{U}$ represent the corresponding upper bound, median and lower bound respectively. When $x^{L}=x^{M}=x^{U}$, they degenerate to real values. They must satisfy the following operation rules:

$$
\begin{gathered}
S_{1} \oplus S_{2}=\left(l_{1}+l_{2}, m_{1}+m_{1}, \mu_{1}+\mu_{2}\right), \\
S_{1} \odot S_{2}=\left(l_{1} l_{2}, m_{1} m_{1}, \mu_{1} \mu_{2}\right) \\
\lambda \odot S_{1}=\left(\lambda l_{1}, \lambda m_{1}, \lambda \mu_{1}\right), \lambda>0, \lambda \in \mathrm{R} \\
S_{1}^{-1} \approx\left(\frac{1}{\mu_{1}}, \frac{1}{m_{1}}, \frac{1}{l_{1}}\right)
\end{gathered}
$$

\subsection{Fuzzy Delphi Method}

Delphi Method was first developed in the 1940s by O. Helm and N. Dahlke and further developed by T. J. Gordon and the Rand Corporation. Delphi method is a systematic procedure, the use of anonymous expression of opinion. This method is widely representative and reliable. However, when dealing with uncertain information, the traditional Delphi method has disadvantages such as poor convergence, distorted expert consciousness and high execution cost. Thus, fuzzy Delphi method is proposed to solve these problems. The method can deal with ambiguity and uncertainty of data and obtain co-decision with a round of written communication of TFN. The specific operation steps are as follows:

Step 1: Design a questionnaire. By using linguistic variables of fuzzy nature to determine the evaluation score of experts on the importance of each indicator attribute, this paper adopts the method of triangular fuzzy number proposed in literature [22], as shown in Table 2. For decision-makers, their attitudes towards different indicators can be expressed by fuzzy variables "strongly agree", "agree", "neutral", "disagree" and "strongly disagree" to express their opinions on the rating of each indicator.

Table 1. Linguistic scales for the importance weight of criteria.

\begin{tabular}{ll}
\hline $\begin{array}{l}\text { The importance of indicators measured by } \\
\text { experts }\end{array}$ & $\begin{array}{l}\text { Corresponding } \\
\text { TFN }\end{array}$ \\
\hline Extremely agree & $(0.7,0.9,1.0)$ \\
Agree & $(0.5,0.7,0.9)$ \\
Neutral & $(0.3,0.5,0.7)$ \\
Disagree & $(0.1,0.3,0.5)$ \\
Extremely disagree & $(0.0,0.1,0.3)$ \\
\hline
\end{tabular}

Step 2: Collect fuzzy trigonometric numbers. For k experts who sent the questionnaire, we can get their ratings of different indicators, which is represented by fuzzy trigonometry. Based on the processing of formula (24), we can obtain the comprehensive fuzzy trigonometric numbers of all experts.

$$
\widetilde{a_{j}}=\left(\min _{i}\left\{l_{i j}\right\}, \frac{1}{n} \sum_{i=1}^{n} m_{i}, \max _{i}\left\{u_{i j}\right\}\right)=\left(l_{j}, m_{j}, u_{j}\right) ; i=1,2, \ldots, k ; j=1,2, \ldots, n,
$$


Where, $l_{j}, m_{j}, u_{j}$ are the minimum value, arithmetic mean value and maximum value of fuzzy number elements. Indicators $\mathrm{i}$ and $\mathrm{j}$ represent expert attribute and quality attribute respectively.

Step 3: Defuzzifying fuzzy trigonometric numbers. There are many methods to defuzzify, among which, we choose the barycenter method for processing, because the barycenter method has a smoother output reasoning control, even corresponding to the small change of input signal, the output will change. Because of its simplicity and convenience, the barycentric method has been used and improved by many scholars.

$$
a_{j}=\frac{l_{j}+m_{j}+u_{j}}{3}, j=1,2, \ldots, k
$$

Where, $a_{j}$ is a defuzzifying number that quantifies the aggregate opinion of all experts on the validity of quality attributes.

Step 4: Check the consistency of expert opinions and screen indicators.

In order to standardize fuzzy numbers, the process mainly focuses on the difference between the average opinion of a single expert and the average opinion of all experts. The facilitator then sends the results back to each expert for an opportunity to revise their previous opinion or to propose a new opinion based on their average opinion or deviation from the overall average opinion for an attribute. After defuzzification, the final quality attribute is selected according to the following logic:

If $a_{j}>\alpha$, the $\mathrm{j}$-th factor is used in the next stage of calculation;

If $a_{j}<\alpha$, the index has been omitted.
Cronbach threshold $\alpha=0.7$ was selected in this paper. Iterations continue until the difference between the average value of each quality attribute and the value of the previous iteration is less than or equal to 0.1 [23].

\subsection{Fuzzy Analytic Hierarchy Process}

As we can see from the description of Fuzzy Delphi Method in the previous section, Fuzzy theory can improve the original method to be closer to real life and better measure uncertainty problems. Therefore, we also introduce the fuzzy set theory to determine the index weight. As mentioned in most studies, AHP method is a common method to solve complex decision-making problems and has been widely applied by professionals and scholars in many different fields. In the traditional AHP method, the pair comparison matrix of each sub-standard is usually given by a nine-level scale table, and the measure scale of importance is a certain number. However, in Fuzzy Delphi, a Fuzzy number is given to solve our problems for each language scale describing importance. Therefore, fuzzy logic can also better solve the inaccuracy of expert opinions for the traditional AHP method [24]. The main steps are as follows:

Step 1: Issue questionnaires to experts and construct pairwise comparison matrices. As Satty proposes, instead of comparing all factors together, compare them in pairs with each other. Relative scale is adopted to minimize the difficulty of comparing factors with different properties, so as to improve accuracy [25]. The language scale and corresponding fuzzy numbers are given in Table 2, so the judgment matrix formed according to the pairwise comparison results is shown in formula (26):

Table 2. Linguistic scale

\begin{tabular}{llc}
\hline Scale & Meaning & Fuzzy Number \\
\hline 1 & Represents two factors of equal importance & $(1,2.3)$ \\
2 & The median value of two adjacent judgments & $(1,2,3)$ \\
3 & Refers to two factors in which one is slightly more important than the other & $(2,3,4)$ \\
4 & The median value of two adjacent judgments & $(3,4,5)$ \\
5 & Represents two factors in which one factor is significantly more important than the other & $(4,5,6)$ \\
6 & The median value of two adjacent judgments & $(5,6,7)$ \\
7 & Refers to two factors in which one is more strongly important than the other & $(6,7,8)$ \\
8 & The median value of two adjacent judgments & $(7,8,9)$ \\
9 & Refers to two factors in which one is more important than the other & $(8,9,9)$ \\
count backwards & If the comparison between factor I and j can judge aij, then the comparison between factor j and I can judge aji=1/aij & \\
\hline
\end{tabular}

$$
\begin{aligned}
\widetilde{A^{k}} & =\left[\begin{array}{cccc}
\tilde{A}_{11}^{k} & \tilde{A}_{12}^{k} & \cdots & \tilde{A}_{1 n}^{k} \\
\tilde{A}_{21}^{k} & \tilde{A}_{22}^{k} & \cdots & \tilde{A}_{2 n}^{k} \\
\vdots & \vdots & \ddots & \vdots \\
\tilde{A}_{n 1}^{k} & \tilde{A}_{n 2}^{k} & \cdots & \tilde{A}_{n n}^{k}
\end{array}\right] \\
i, j & =1,2, \ldots, n ; k=1,2, \ldots, m .,
\end{aligned}
$$

Where, $\tilde{A}_{i j}^{k}$ refers to the number of experts' preferences for the $\mathrm{i}$ indicator relative to the $\mathrm{j}$ indicator when they make decisions. $\tilde{A}_{i j}^{k}=\left(l_{i j}, m_{i j}, u_{i j}\right)$, which also satisfy the constraint of triangular fuzzy number, $l_{i j} \leq m_{i j} \leq u_{i j}$.
In order to obtain the final comprehensive evaluation matrix, we used geometric mean to calculate the average preference of each expert for each factor, as shown in Formula (27).

$$
A_{i j}=\left(\prod_{k=1}^{m} \tilde{A}_{i j}^{k}\right)^{1 / k}
$$

In this case, the comprehensive judgment matrix becomes:

$$
\mathrm{A}=\left(\begin{array}{ccc}
\tilde{A}_{11} & \cdots & \tilde{A}_{1 n} \\
\vdots & \ddots & \vdots \\
\tilde{A}_{n 1} & \cdots & \tilde{A}_{n n}
\end{array}\right)
$$


Step 2: Conduct consistency test for the judgment matrix. In the consistency test, we use the method in reference [26] to conduct a better consistency test for the judgment matrix under fuzzy sets.

Firstly, we transform the triangular fuzzy numbers $A_{i j}=\left(l_{i j}, m_{i j}, u_{i j}\right)$ into two independent matrices, where the first matrix generated by the middle number is $A_{m}=\left[m_{i j}\right]$, and the second matrix generated by the geometric mean of the upper and lower bounds is $A_{g}=\left[\sqrt{u_{i j} \times l_{i j}}\right]$. Now, we can get three matrices, respectively: A, $A_{m}, A_{g}$.

Next, we carry out consistency test for each matrix respectively, follow the process of general AHP method, calculate the corresponding maximum eigenvalue $\lambda_{\max }$, and solve the consistency index. The consistency index $\mathrm{CI}, C I_{m}, C I_{g}$ of different matrices were obtained, and the consistency ratio was $C R, C R_{m}, C R_{g}$ respectively.

$$
\begin{gathered}
\mathrm{A} \times w=\lambda_{\max } \times \mathrm{w}, \\
\lambda_{\max }=\frac{1}{\mathrm{n}} \sum_{\mathrm{i}=1}^{\mathrm{n}} \sum_{\mathrm{j}=1}^{\mathrm{n}} \mathrm{A}_{\mathrm{ij}}\left(\mathrm{w}_{\mathrm{j}} / \mathrm{w}_{\mathrm{i}}\right), \\
C I=\frac{\lambda_{\max }-n}{n-1}, \\
C T=\frac{C I}{R I}
\end{gathered}
$$

Normally, when CR value is less than 0.1 , it is considered that the inconsistency degree of judgment matrix is within the allowable range and has a relatively satisfactory consistency, which can pass the consistency test. Otherwise, pair-comparison matrix should be reconstructed and adjusted. Among them, the value of random consistency index RI is shown in Table 3. This paper only gives the RI values of matrices with less than 7 orders. If necessary, RI values of more orders given in reference [27] can be referred to.

Table 3. The value of RI.

\begin{tabular}{llll}
\hline Size of the matrix & $\boldsymbol{R} \boldsymbol{I}$ & $\boldsymbol{R I}_{\boldsymbol{m}}$ & $\boldsymbol{R I}_{\boldsymbol{q}}$ \\
\hline 1 & 0 & 0 & 0 \\
2 & 0 & 0 & 0 \\
3 & 0.52 & 0.4890 & 0.1796 \\
4 & 0.89 & 0.7937 & 0.2627 \\
5 & 1.12 & 1.0720 & 0.3597 \\
6 & 1.26 & 1.1996 & 0.3818 \\
7 & 1.36 & 1.2874 & 0.4090 \\
\hline
\end{tabular}

Step 3: Determine the fuzzy weight. In order to better explain the relevant theories in this section, we first introduce the concept of fuzzy set correlation. First, we can take $\mathrm{X}=\left\{\mathrm{x}_{1}, \mathrm{x}_{2}, \ldots, \mathrm{x}_{\mathrm{n}}\right\}$ as an object set, $\mathrm{U}=\left\{\mathrm{u}_{1}, \mathrm{u}_{2}, \ldots, \mathrm{u}_{\mathrm{m}}\right\}$ as a goal set. We can now set the object sets for each goal. Therefore, for each object, we can obtain $\mathrm{m}$ object values, as shown in formula (33):

$$
M_{g i}^{1}, M_{g i}^{2}, \ldots, M_{g i}^{m}, i=1,2, \ldots, n,
$$

The $M_{g i}^{m}$ values here are all triangle fuzzy numbers.

In addition, we also have the definition, the value of fuzzy synthetic extent with respect to the i-th object is defined as formula (34).

$$
S_{i}=\sum_{j=1}^{m} M_{g i}^{j} \odot\left[\sum_{i=1}^{n} \sum_{j=1}^{m} M_{g i}^{j}\right]^{-1},
$$

Take $S_{1}$ and $S_{2}$ as an example, the next step should follow the description in formula (34).

$$
\begin{gathered}
\mathrm{V}\left(S_{2}>S_{1}\right)=\operatorname{highest}\left(S_{1} \cap S_{2}\right)=\mu_{s 2}(d), \\
\mu_{s 2}(d)=\left\{\begin{array}{c}
1, \text { if } m_{2} \geq m_{1} \\
0, \text { if } l_{1} \geq u_{2} \\
\frac{l_{1}-u_{2}}{\left(m_{1}-u_{2}\right)-\left(m_{1}-l_{1}\right)}, \text { otherwise }
\end{array}\right.
\end{gathered}
$$

Through calculation, we can obtain the relative comparison value of $n$-dimensional indicators, including N-1 data. Among the $n-1$ data corresponding to each indicator, we need the smallest data as the initial weight value of this indicator.

$$
\tilde{p}_{\imath}=\operatorname{MIN}\left(\mu_{s i}(d)\right) \text {, }
$$

Then, we can get the final weight value of the $\mathrm{N}$-dimensional index through normalization.

$$
W_{k}=\left(p_{1}, p_{2}, \ldots, p_{n}\right),
$$

\subsection{BP Neural Network}

Artificial Neural Network (ANN) is a theoretical mathematical model of human brain Neural Network. By modifying network interconnection weights through training and learning process, neural network can complete the required input-output mapping. The principle of neural network is to establish a similar operation mechanism of data with the neural system of biological brain, design a similar structure and function with the biological neural network, and connect a large number of simple neurons to form an artificial intelligence network system that can carry out information processing, storage and retrieval.

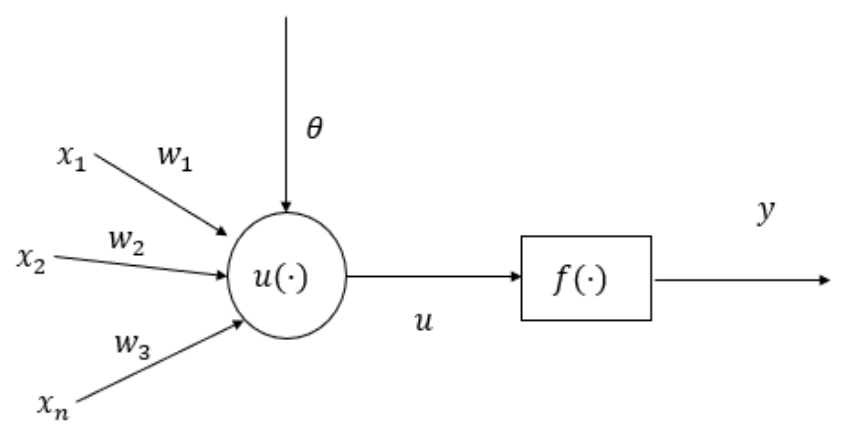

Figure 3. The neural network.

BP neural network is one of the most widely used neural network models. BP network can learn and store a large number of input-output mode mappings without revealing the mathematical equations describing the mappings in advance. Its learning rule is to use the fastest descent method, through back propagation to constantly adjust the weight and threshold of the network, so as to minimize the sum of squares of error of the network. The learning process consists of two processes: signal forward propagation and error back propagation. In the forward propagation, the input sample is introduced from the 
input layer and then transmitted to the output layer after being processed layer by layer by layer. If the actual output of the output layer is not consistent with the expected output, then it enters the back-propagation stage of error. When back-propagation, the output is transmitted back to the input layer layer by layer through the hidden layer in some form, and the error is apportioned to all the units of each layer, so as to obtain the error signal of each unit, and this error signal is used as the basis for correcting the weight of each unit.

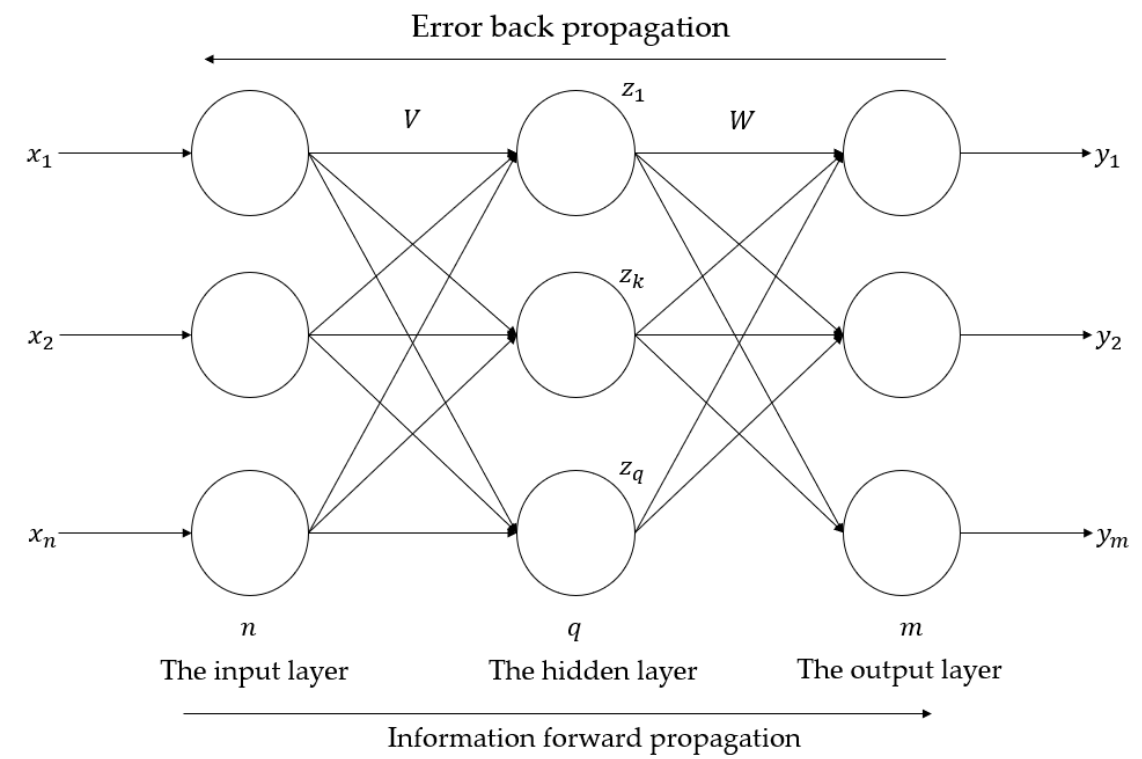

Figure 4. Neuronal information transmission process.

BP neural network algorithm mainly uses the following steps:

Step 1: Data preprocessing

During network input, some problems are often encountered, such as the difference of magnitude or unit of data variable, which makes the training effect of neural network not good. When the $\mathrm{S}$ function is used as the activation function, the range is within $(0,1)$, so the data should be normalized before the neural network training data, that is, the data to be trained should be converted to a range of $[-1,1]$ or $[0,1]$ or a smaller range. There are two general normalization algorithms.

(1) Maximum and minimum method

$$
x=\frac{x_{i}-x_{\min }}{x_{\max }-x_{\min }}
$$

Where, $x$ is the dimensionless index; $x_{i}$ is the original index value of this index; $x_{\min }$ is the minimum value of the original index value of this index in all evaluation objects; $x_{\max }$ is the maximum value of the original index of this item in all evaluation objects.

(2) Mean variance method

$$
x=\frac{x_{i}-x_{\text {mean }}}{x_{\text {var }}}
$$

Where, $x_{\text {mean }}$ is the average value of the original index of this item in all evaluation objects; $x_{v a r}$ is the variance of the original index value of this index in all evaluation objects.

Step 2: Calculation process

Input and output of network intermediate layer and output layer are calculated according to formula (41) and formula (42) respectively:

$$
\begin{aligned}
& x_{j}^{\prime}=f\left(\sum_{i=1}^{m} w_{j i} x_{i}-\theta_{j}\right), \\
& x y_{k}^{\prime}=f\left(\sum_{k=1}^{l} w_{k j} x_{j}^{\prime}-\theta_{j}\right),
\end{aligned}
$$

Where, $x_{j}^{\prime}$ is the output of the middle layer; $y_{k}^{\prime}$ is the response of each unit in the output layer; $w_{j i}, w_{k j}$ are connection weights; $\theta_{j}$ is the threshold.

The calculation of unit error of each module in the middle layer is as follows:

$$
\sigma_{j}=x_{j}^{\prime}\left(1-x_{j}^{\prime}\right) \sum_{k=1}^{l} \delta_{k} w_{k j},
$$

Where, $\sigma_{j}$ is the element error of each module in the middle layer; $\delta_{k}$ is the unit error of each module in the output layer.

The error adjustment of each layer is shown in the equation (44).

$$
\begin{gathered}
w_{k j}(N+1)=w_{k j}(N)+a \delta_{k} x_{j}^{\prime}, \\
w_{j i}(N+1)=w_{j i}(N)+\beta \sigma_{j} x_{i},
\end{gathered}
$$

By setting the size of the parameter, the error between the training times and the expectation is set in advance. If either of the two is satisfied, the training is judged to be over.

Step 3: Weight calculation

The ultimate goal of neural network learning is to determine the weight of input evaluation indexes, that is, to determine the weight relationship between input indexes and output indexes, that is, the relationship between independent variables and dependent variables. Therefore, the weight between each neuron should be further analyzed and processed. 
When the network training meets the accuracy requirements, the training ends, and the connection weight matrix $\mathrm{V}$ between the output input layer and each hidden layer is obtained, from which the input weight of each neuron in the input layer can be calculated. Such as:

$$
w_{j}=\frac{\sum_{l=1}^{k}\left|v_{i l}\right|}{\sum_{i=1}^{m} \sum_{l=1}^{k}\left|v_{i l}\right|} \mathrm{j}=1,2, \ldots \ldots, \mathrm{m}
$$

\section{Case Study}

This paper selects the relevant data of power market operation in a region in five months to construct an index system and evaluate it.

\subsection{Establishment of Index System}

\subsubsection{Index Selection Based on Fuzzy Delphi}

Based on the previous research, the establishment of the index system was carried out at first.

Here, fuzzy-Delphi method is applied to perform primary screening of the index system. The steps are as follows:

Step 1: Five expert groups are selected for further professional evaluation. They are all experts in different fields, including government departments, power market operators, power industry regulators, university professors and graduate students engaged in power market research. Refer to Table 4 for the language ambiguity of specific scoring. The scoring scale is as follows:

Table 4. Expert grading scale.

\begin{tabular}{|c|c|c|c|c|}
\hline Index & Group 1 & Group 2 & Group 3 & Group 4 \\
\hline $\mathrm{B} 1$ & $(0.1,0.3,0.5)$ & $(0.1,0.3,0.5)$ & $(0.1,0.3,0.5)$ & $(0.1,0.3,0.5)$ \\
\hline B2 & $(0.1,0.3,0.5)$ & $(0.1,0.3,0.5)$ & $(0.1,0.3,0.5)$ & $(0.1,0.3,0.5)$ \\
\hline B3 & $(0.5,0.7,0.9)$ & $(0.7,0.9,1)$ & $(0.5,0.7,0.9)$ & $(0.5,0.7,0.9)$ \\
\hline B4 & $(0.3,0.5,0.7)$ & $(0.3,0.5,0.7)$ & $(0.5,0.7,0.9)$ & $(0.3,0.5,0.7)$ \\
\hline B5 & $(0.7,0.9,1)$ & $(0.5,0.7,0.9)$ & $(0.7,0.9,1)$ & $(0.7,0.9,1)$ \\
\hline B6 & $(0.3,0.5,0.7)$ & $(0.1,0.3,0.5)$ & $(0.3,0.5,0.7)$ & $(0.3,0.5,0.7)$ \\
\hline B7 & $(0.5,0.7,0.9)$ & $(0.5,0.7,0.9)$ & $(0.3,0.5,0.7)$ & $(0.5,0.7,0.9)$ \\
\hline B9 & $(0.7,0.9,1)$ & $(0.5,0.7,0.9)$ & $(0.7,0.9,1)$ & $(0.5,0.7,0.9)$ \\
\hline B10 & $(0.7,0.9,1)$ & $(0.7,0.9,1)$ & $(0.7,0.9,1)$ & $(0.5,0.7,0.9)$ \\
\hline B11 & $(0.1,0.3,0.5)$ & $(0.3,0.5,0.7)$ & $(0.1,0.3,0.5)$ & $(0.1,0.3,0.5)$ \\
\hline B12 & $(0.1,0.3,0.5)$ & $(0.3,0.5,0.7)$ & $(0.1,0.3,0.5)$ & $(0.1,0.3,0.5)$ \\
\hline B13 & $(0.5,0.7,0.9)$ & $(0.7,0.9,1)$ & $(0.7,0.9,1)$ & $(0.5,0.7,0.9)$ \\
\hline B14 & $(0.5,0.7,0.9)$ & $(0.5,0.7,0.9)$ & $(0.5,0.7,0.9)$ & $(0.5,0.7,0.9)$ \\
\hline B15 & $(0.5,0.7,0.9)$ & $(0.7,0.9,1)$ & $(0.5,0.7,0.9)$ & $(0.5,0.7,0.9)$ \\
\hline B18 & $(0.7,0.9,1)$ & $(0.5,0.7,0.9)$ & $(0.7,0.9,1)$ & $(0.5,0.7,0.9)$ \\
\hline B19 & $(0.5,0.7,0.9)$ & $(0.7,0.9,1)$ & $(0.5,0.7,0.9)$ & $(0.7,0.9,1)$ \\
\hline B20 & $(0.5,0.7,0.9)$ & $(0.7,0.9,1)$ & $(0.7,0.9,1)$ & $(0.7,0.9,1)$ \\
\hline B21 & $(0.5,0.7,0.9)$ & $(0.5,0.7,0.9)$ & $(0.5,0.7,0.9)$ & $(0.7,0.9,1)$ \\
\hline B22 & $(0.7,0.9,1)$ & $(0.5,0.7,0.9)$ & $(0.5,0.7,0.9)$ & $(0.5,0.7,0.9)$ \\
\hline B23 & $(0.5,0.7,0.9)$ & $(0.7,0.9,1)$ & $(0.7,0.9,1)$ & $(0.5,0.7,0.9)$ \\
\hline B24 & $(0.5,0.7,0.9)$ & $(0.5,0.7,0.9)$ & $(0.5,0.7,0.9)$ & $(0.7,0.9,1)$ \\
\hline
\end{tabular}

Step 2: Collect fuzzy trigonometric numbers. For k experts who sent the questionnaire, we can get their ratings of different indicators, which is represented by fuzzy trigonometry. Through the processing of formula (24), we can obtain the comprehensive fuzzy trigonometric number under the concentration of all experts.

Table 5. Comprehensive fuzzy trigonometry under secondary index of market structure.

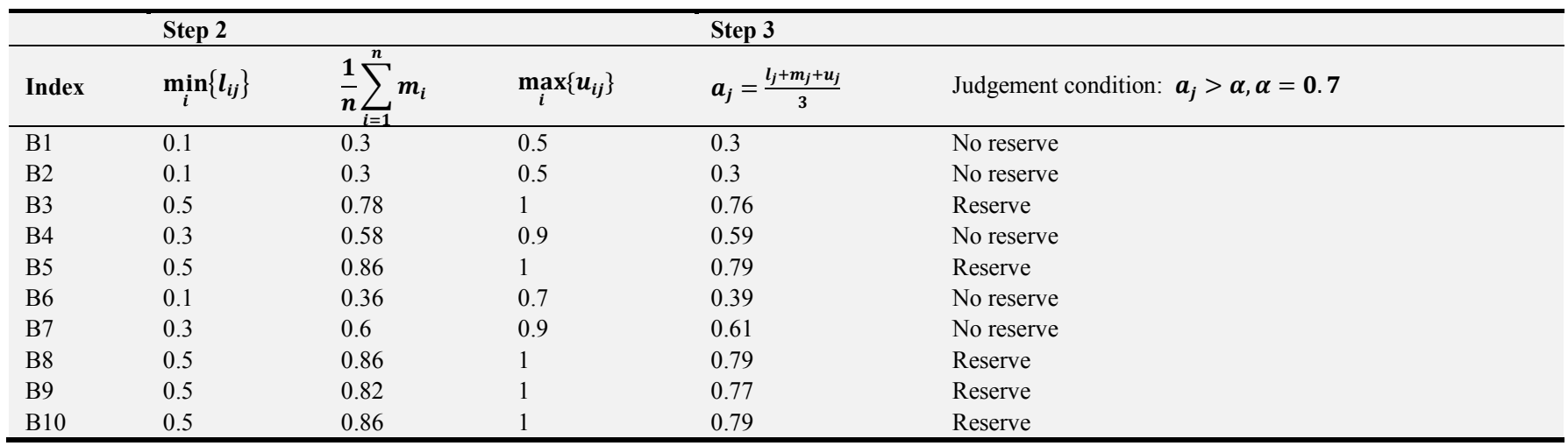

Similarly, indicators under market behavior and market performance can be evaluated by experts. Therefore, the index system processed by fuzzy-Delphi method is shown in Table 6 . 
Table 6. The index system screened by fuzzy-Delphi method.

\begin{tabular}{lll}
\hline & Reserved index & Non-reserved index \\
\hline \multirow{5}{*}{ Market structure } & B3 & B1 \\
& B5 & B2 \\
& B8 & B4 \\
& B9 & B6 \\
& B10 & B7 \\
Market behavior & B13 & B11 \\
& B14 & B12 \\
& B15 & B17 \\
& B19 & B18 \\
& B20 & B23 \\
Market performance & B21 & B24 \\
& B22 & \\
\hline
\end{tabular}

\subsubsection{The Index Weight Determined Based on Fuzzy AHP}

On the basis of the index system construction in section 2.2, fuzzy-AHP method is used to determine the weight of the index system. The steps are as follows:

Step 1: Issue questionnaires to experts, and ask them to score the importance of indicators at all levels in pairs according to the traditional AHP method. In the process of index, according to the given fuzzy scale for processing, will be obtained from each expert pairings for processing. All opinions of different expert groups are summarized to obtain the comprehensive judgment matrix, as shown in Table 7:

Table 7. Pairwise judgment matrix under the first-level index of market structure.

\begin{tabular}{llllll}
\hline & B3 & B5 & B8 & B9 & B10 \\
\hline B3 & $1,1,1$ & $0.34,0.51,0.82$ & $0.45,0.66,1.15$ & $0.6,0.82,1.06$ & $0.49,0.8,1$ \\
B5 & $1.22,1.97,2.93$ & $1,1,1$ & $1.32,2.09,3.06$ & $0.94,1.32,1.82$ & $1.15,1.64,2.27$ \\
B8 & $0.87,1.52,2.22$ & $0.33,0.48,0.76$ & $1,1,1$ & $0.58,0.82,1.22$ & $0.77,1.02,1.4$ \\
B9 & $0.94,1.22,1.66$ & $0.55,0.76,1.06$ & $0.82,1.22,1.72$ & $1,1,1$ & $0.76,1.06,1.5$ \\
B10 & $1,1.25,2.05$ & $0.44,0.61,0.87$ & $0.72,0.98,1.3$ & $0.67,0.94,1.32$ & $1,1,1$ \\
\hline
\end{tabular}

Step 2: Conduct a consistency check.

Taking the secondary index under the market structure as an example, the consistency index of the initial judgment matrix and the comprehensive judgment matrix was calculated. After calculation, the judgment matrix obtained by the five expert groups all met the consistency test. For the comprehensive judgment matrix, the consistency index values all met the consistency test. The calculated consistency index values are shown in the following table:

Table 8. Consistency test under the first-level index of market structure.

\begin{tabular}{llllllll}
\hline & & The matrix order & RI & CI & CR & Criteria & Whether the consistency test is passed \\
\hline & Group 1 & 5 & 1.12 & 0.0207 & 0.0184 & CR $=0.0184<0.10$ & $\sqrt{ }$ \\
Independent & Group 2 & 5 & 1.12 & 0.0445 & 0.0397 & CR $=0.0397<0.10$ & $\sqrt{ }$ \\
matrix test & Group 3 & 5 & 1.12 & 0.0307 & 0.0274 & CR=0.0274<0.10 & $\sqrt{ }$ \\
& Group 4 & 5 & 1.12 & 0.0359 & 0.0321 & CR=0.0321<0.10 & $\sqrt{ }$ \\
comprehensiv & $A_{m}$ & 5 & 1.12 & 0.1110 & 0.0991 & CR=0.0991<0.10 & $\sqrt{ }$ \\
e judgment & $A_{g}$ & 5 & 1.0720 & 0.0073 & 0.0068 & CR=0.0068<0.10 & $\sqrt{ }$ \\
\hline
\end{tabular}

Step 3: Determine the weight of indicators

Through the calculation of formula (36), (37) and (38), the weight of each indicator can be obtained, as shown in the table. Take market structure indicators as an example:

Table 9. Fuzzy Synthetic Extent and degree of possibility for each attributes.

\begin{tabular}{|c|c|c|c|c|c|c|c|c|c|c|}
\hline \multicolumn{11}{|c|}{ Fuzzy Synthetic Extent, Degree of Possibility, Weights for the Attributes with Respects to the Objective } \\
\hline Alternatives & Fuzzy & ntheti & tent & & & & & & Degree of Possibility & Normalization \\
\hline B3 & 0.08 & 0.14 & 0.25 & & 0.38 & 0.80 & 0.72 & 0.80 & 0.38 & 0.12 \\
\hline B5 & 0.16 & 0.30 & 0.56 & 1.00 & & 1.00 & 1.00 & 1.00 & 1.00 & 0.31 \\
\hline B8 & 0.10 & 0.18 & 0.33 & 1.00 & 0.59 & & 0.93 & 1.00 & 0.59 & 0.19 \\
\hline B9 & 0.11 & 0.20 & 0.35 & 1.00 & 0.65 & 1.00 & & 1.00 & 0.65 & 0.20 \\
\hline B10 & 0.11 & 0.18 & 0.33 & 1.00 & 0.59 & 0.99 & 0.92 & & 0.59 & 0.18 \\
\hline
\end{tabular}

Table 10. The weight of each indicator.

\begin{tabular}{|c|c|c|c|c|}
\hline Aspects & Weight 1 & Index & Weight 2 & Normalized weight \\
\hline \multirow{5}{*}{ A1 } & \multirow{5}{*}{0.28} & B3 & 0.12 & 0.03 \\
\hline & & B5 & 0.31 & 0.09 \\
\hline & & B8 & 0.19 & 0.05 \\
\hline & & B9 & 0.20 & 0.06 \\
\hline & & $\mathrm{B} 10$ & 0.18 & 0.05 \\
\hline
\end{tabular}




\begin{tabular}{lllll}
\hline Aspects & Weight 1 & Index & Weight 2 & Normalized weight \\
\hline & & B13 & 0.18 & 0.07 \\
A2 & B14 & 0.45 & 0.19 \\
& 0.41 & B15 & 0.21 & 0.09 \\
& B16 & 0.16 & 0.06 \\
A3 & B19 & 0.32 & 0.10 \\
& \multirow{2}{*}{0.30} & B20 & 0.37 & 0.11 \\
& & B21 & 0.31 & 0.09 \\
\hline
\end{tabular}

The method for determining the weight of secondary indicators under market behavior and market performance is the same. The weight of the final indicator can be obtained as shown in Table 10. Two decimal digits are reserved in this paper, and the original digits are retained in the calculation process.

\subsection{Comprehensive Assessment}

\subsubsection{Index Calculation Results}

(1) Market structure
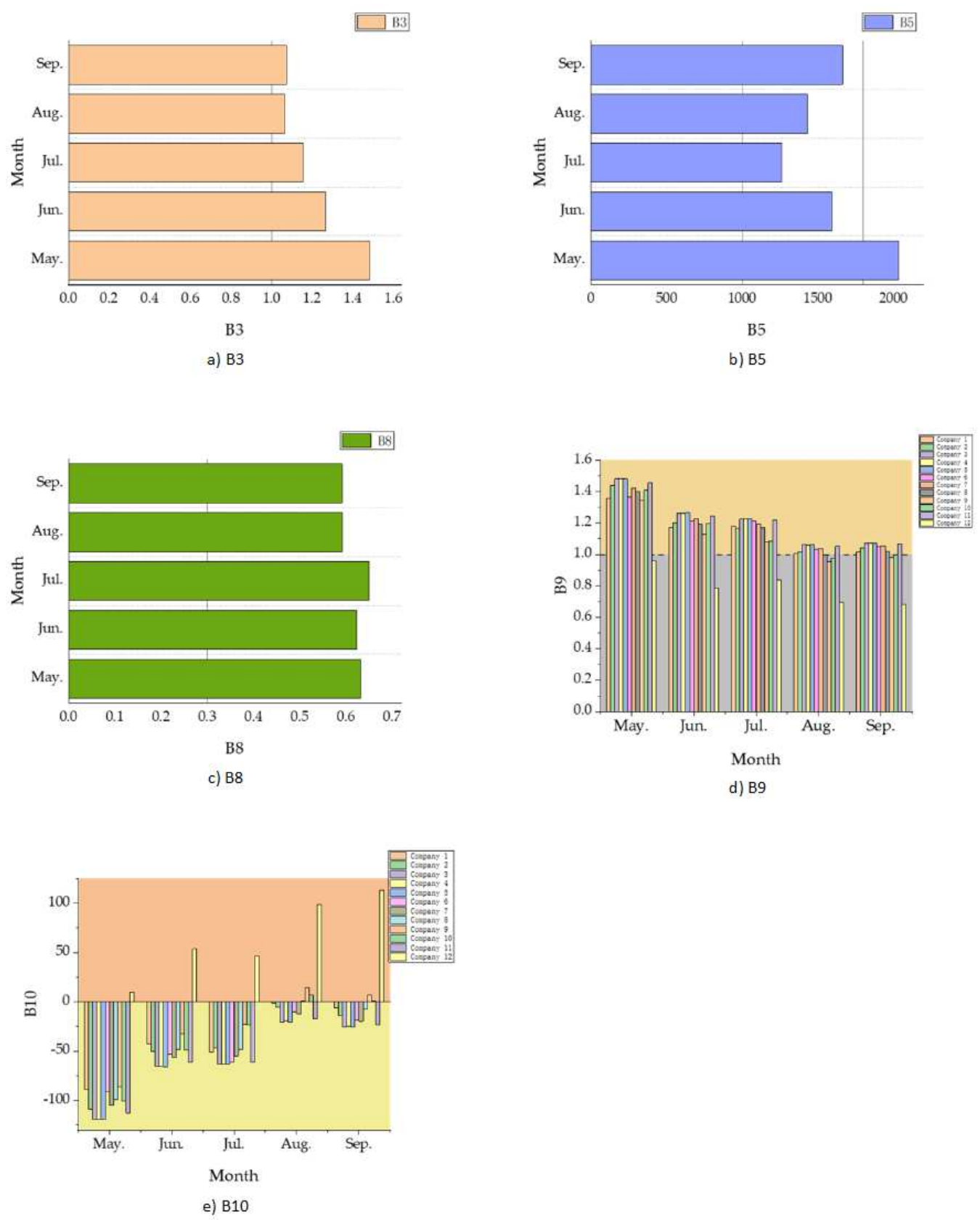

Figure 5. Performance of indicators at all levels of the market structure. 
Through data analysis and calculation of indicators, the calculation results of each indicator can be obtained, as shown in the Figure 5. According to the calculation results, the market reported power supply/demand ratio was greater than 1 in all the five months. In the last two months, the index had a small range of greater than 1 , indicating that the market tended to be competitive and operated well.

From the market HHI index, the monthly concentrated competition market belongs to the state of low concentration oligopoly, and the competition is relatively full. CR4 index, surplus supply rate index and key supplier index measure whether enterprises with larger market share have the tendency to exercise market power. The calculated CR4 index is more than $30 \%$. From the index calculation of surplus supply rate, it can be seen that the index of Company 12 is all less than 1, and other groups also have periods of less than 1 . In the calculation of key supplier index, Company 12 is all the key supplier in the five months of statistics, but the measurement of key supplier is not absolute. Each month correspondingly, there will be other groups as a member of the key supplier with the ability to exercise market power. Overall, Company 12 has a large market share and is a key supplier with the potential to manipulate the market.

The market power index HHI of this province is within the controllable range, HHI is less than 1800 after May, and the calculated $\mathrm{CR}_{4}$ index is more than $30 \%$, indicating that the market players of this province are diversified, and the largest power generation enterprises do not play a monopoly role in

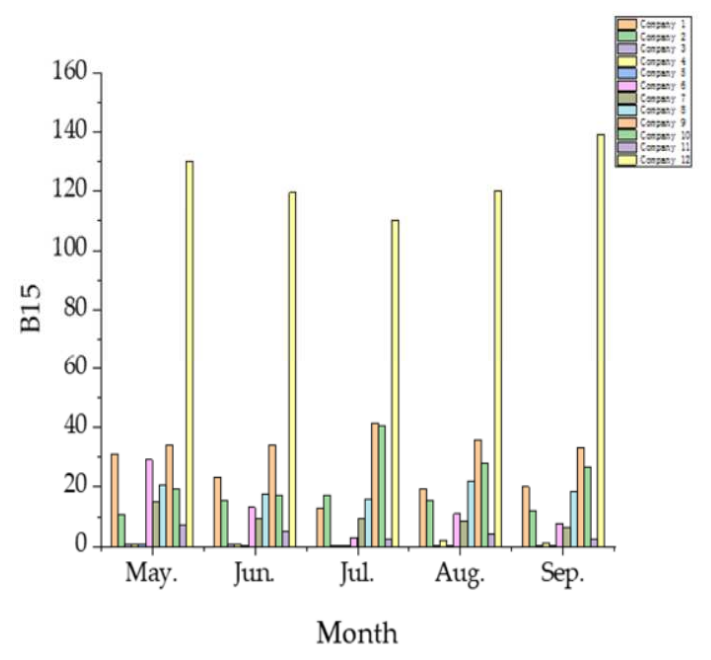

a) B15 the market.

\section{(2) Market behavior}

The relevant data are calculated to obtain the calculation results of market behavior indicators. Among them, bid-ask spread and declared price are presented in Figure 6, and their fluctuations are shown in a broken line chart. Monthly declared electric quantity and transaction rate of declared electric quantity of each power generation group are reflected in Figure 7.

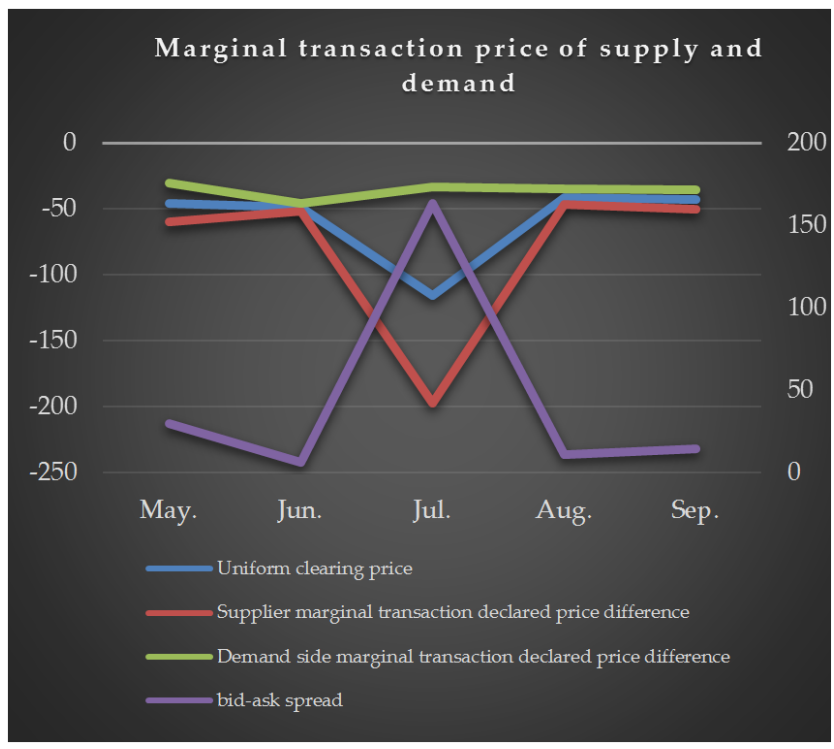

Figure 6. Analysis of quotations from both sides.

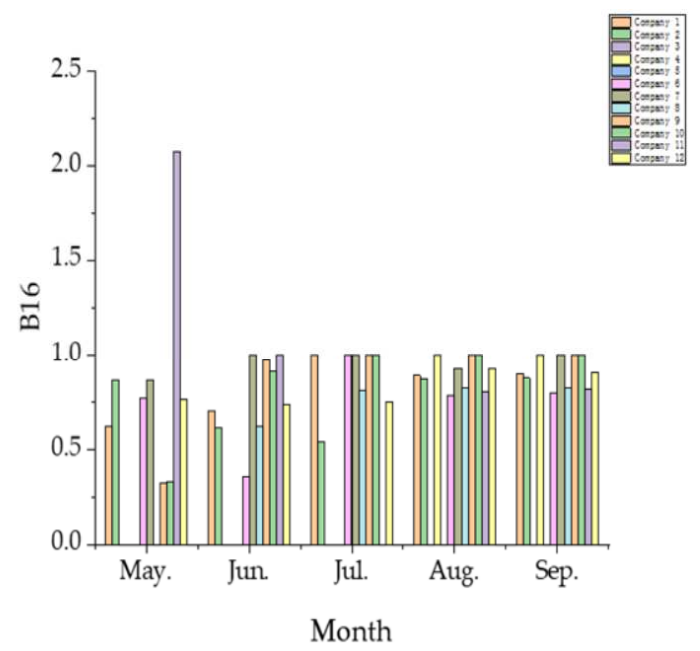

b) B16

Figure 7. Performance of market declared electricity related indicators.

Note: b) the area where the columnar structure is zero indicates that the electric quantity declared by the power generation company in that month has not been transacted.

Buyer and seller quotation overall in a stable state, bid-ask spread also maintained a relatively stable trend. However, in July, the bid-ask spread increased, and the marginal transaction declared spread of the supplier decreased. There was an obvious downward trend in the reported spread chart, indicating that the power producer had maliciously disturbed the market order. The declared electric quantity related indexes of power generation companies reflect the power generation companies' ability to influence the market price. Through the analysis of each group, it can be seen that Company 12 is more likely to influence the electricity price through the unsold electric quantity by virtue of its own share. 
(3) Market performance

Relevant indexes of market performance are calculated as shown in the figure below:

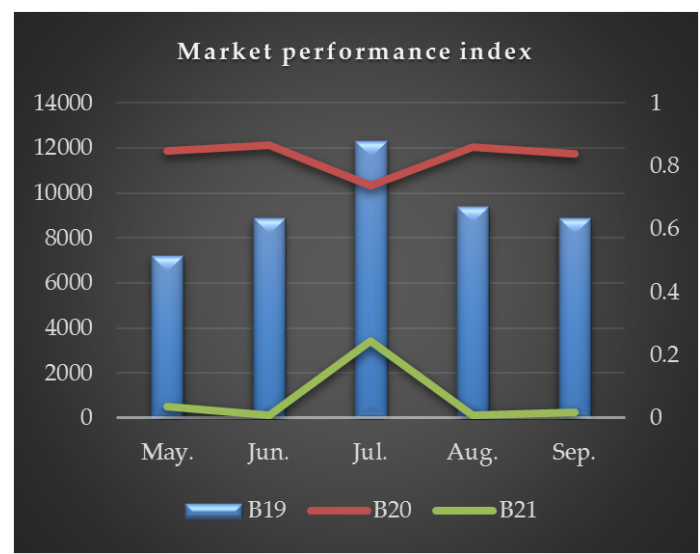

Figure 8. The performance of market performance related indicators.

Through the analysis and calculation of relevant indicators of market performance, it can be seen that the calculation results of these indicators are generally within the standard range of the competitive market. However, the data trend of July is different from that of other months. The Lenard index and the total efficiency of market operation are in a state of low competition, but the producer surplus of this month is large. The analysis may be that the quotation behavior of market suppliers affects the efficiency of the whole market, and there may be monopoly market to exercise market power.

\subsubsection{BP Neural Network Training}

Based on the existing relevant data, this paper uses Monte Carlo simulation method to generate 50 groups of relevant data as training samples. The evaluation results adopt the weighted average operator in fuzzy comprehensive evaluation, taking the comprehensive effect of multiple indicators into account, which better conforms to the actual situation. In 50 groups of samples, 40 groups of samples were selected as the training set, 10 groups of samples as the test set, and the model was trained according to the constructed BP neural network. On the basis of neural network training, real data is used as input to obtain the evaluation results of each month.

(1) Determination of the number of network layers

The number of layers of neural network will have a certain influence on the size of network training error. Insufficient layers will increase the error, while too many layers will lead to too complex network model and reduce the generalization ability of the model. Robert Hecht-Nielson proposed that choosing a three-layer neural network can ensure enough accuracy for realizing the mapping from $\mathrm{N}$ dimension to $\mathrm{M}$ dimension [28]. Therefore, this paper adopts the three-layer BP neural network model.

(2) Determination of the number of neurons at each layer

In terms of the number of neurons in the input layer and the output layer, the evaluation index system of the electricity market operation monitoring constructed in this paper contains $\mathrm{X}$ evaluation indexes, so the number of neurons in the input layer $\mathrm{m}=10$, the output vector is the evaluation result, and the dimension is 1 , so the number of neurons in the output layer $n=1$.

In terms of determining the number of hidden layer neurons, this paper adopts the empirical formula $\mathrm{K}=\sqrt{m+n}+a$ for the number of hidden layer nodes, where $a \in[1,10]$. Therefore, for the purpose of this paper, the location interval of the number of hidden layer nodes is within $[5,13]$, and the errors under the number of hidden layer nodes are analyzed respectively, which can be obtained as follows:

Table 11. Errors under different number of nodes in hidden layers.

\begin{tabular}{llll}
\hline Number of hidden layer nodes & MAE & MSE & RMSE \\
\hline 5 & 0.0048316 & $4.545 \mathrm{e}-05$ & 0.0067416 \\
6 & 0.013915 & 0.00026166 & 0.016176 \\
7 & 0.016835 & 0.00045204 & 0.021261 \\
8 & 0.034319 & 0.0017826 & 0.042221 \\
9 & 0.010445 & 0.00013742 & 0.011723 \\
10 & 0.022113 & 0.00068738 & 0.026218 \\
11 & 0.021823 & 0.00057981 & 0.024079 \\
12 & 0.023827 & 0.0010896 & 0.033009 \\
13 & 0.015319 & 0.00030759 & 0.017538 \\
\hline
\end{tabular}

According to the table, when the number of hidden layer nodes is 5 , the error is minimum, so the number of hidden layer nodes is 5 . Under the condition that the number of hidden layer nodes is 5, the neural network toolbox in MATLAB is used to train the model, and the trained neural network is obtained within the allowable range of error.

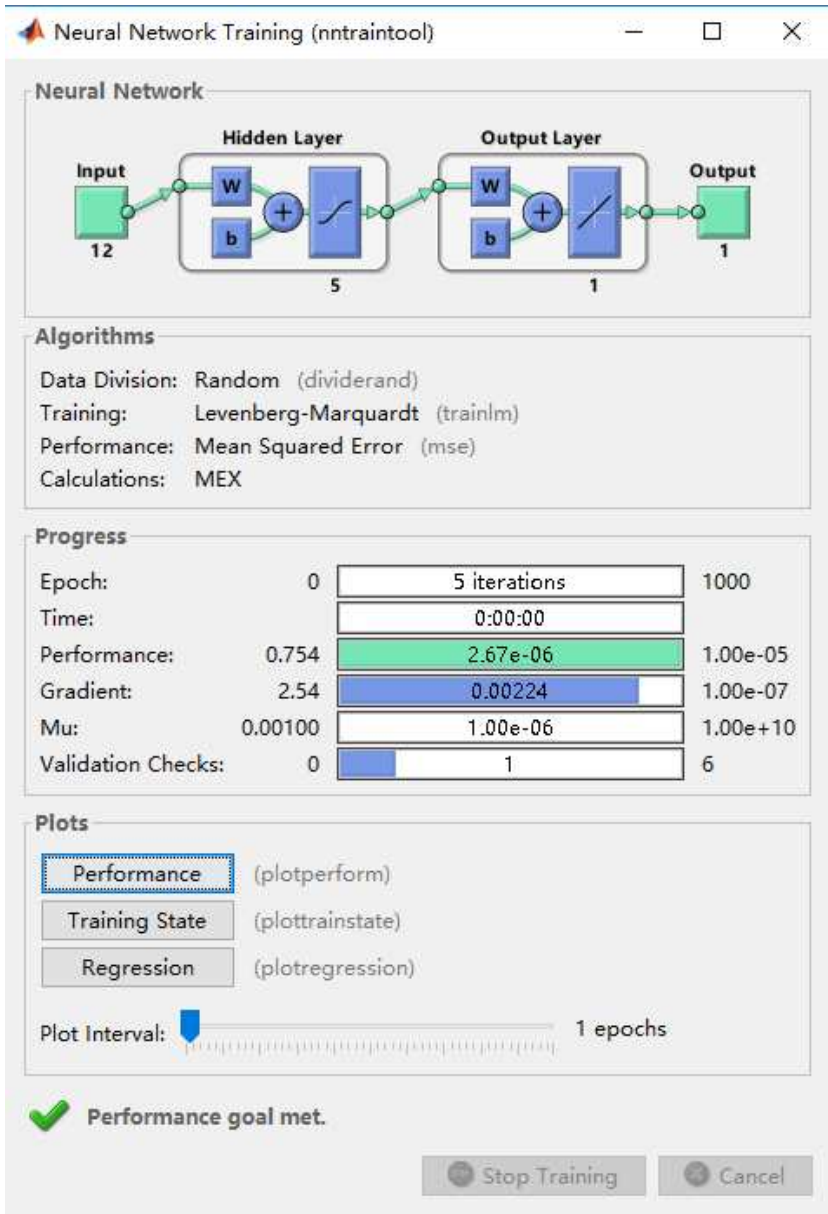

Figure 9. Neural network training structure. 


\subsubsection{BP Neural Network Evaluation}

Table 12 shows the selected region related indicators of grade five months, using the trained neural network to evaluate, can get the final evaluation results as shown in table 13, among them, it can be seen that the fourth sample evaluation score the highest, the third sample evaluation score the lowest, August market overall situation, the best overall performance is poor in July.

Table 12. Monthly evaluation values.

\begin{tabular}{llllll}
\hline & May. & Jun. & Jul. & Aug. & Sept. \\
\hline B1 & 0.6 & 0.8 & 0.9 & 1 & 1 \\
B2 & 0.5 & 0.8 & 0.9 & 0.8 & 0.7 \\
B3 & 0.6 & 0.6 & 0.5 & 0.7 & 0.7 \\
B4 & 0.9 & 0.8 & 0.8 & 0.7 & 0.7 \\
B5 & 0.8 & 0.8 & 0.8 & 0.6 & 0.6 \\
B6 & 0.8 & 0.8 & 0.6 & 0.8 & 0.8 \\
B7 & 0.8 & 0.8 & 0.6 & 0.8 & 0.8 \\
B8 & 0.6 & 0.6 & 0.8 & 0.6 & 0.6 \\
B9 & 0.6 & 0.7 & 0.7 & 0.8 & 0.8 \\
B10 & 0.6 & 0.6 & 0.7 & 0.6 & 0.6 \\
B11 & 0.7 & 0.6 & 0.8 & 0.6 & 0.7 \\
B12 & 0.9 & 0.9 & 0.5 & 0.9 & 0.9 \\
\hline
\end{tabular}

Table 13. Monthly final evaluation score.

\begin{tabular}{llllll}
\hline & May. & Jun. & Jul. & Aug. & Sept. \\
\hline Evaluation score & 0.71757 & 0.72248 & 0.68787 & 0.73758 & 0.72750 \\
\hline
\end{tabular}

\subsection{Sensitivity Analysis}

In order to better analyze the indicators in the evaluation model, we conducted sensitivity analysis for the indicators in the best and worst performing months. In terms of method selection, we used normalized specific evaluations as the valuation of an index, including $0.2,0.4,0.6,0.8$ and 1 , respectively, to obtain five different samples, which were used as the input of BP neural network, recorded the maximum output and minimum output, and took the ratio of their maximum output as the single sensitivity of the index [29].

Table 14. Numerical sensitivity calculation.

\begin{tabular}{llll}
\hline Aspects & Index & Aug. & Jul. \\
\hline & B3 & 0.025326607 & 0.014284065 \\
A1 & B5 & 0.062770927 & 0.028080196 \\
& B8 & 0.11354887 & 0.071189859 \\
& B9 & 0.088430161 & 0.003621565 \\
& B10 & 0.055366337 & 0.093928702 \\
A2 & B13 & 0.032256729 & 0.027492769 \\
& B14 & 0.173224707 & 0.094575048 \\
& B15 & 0.102003624 & 0.120898726 \\
A3 & B16 & 0.142388004 & 0.065267086 \\
& B19 & 0.056583247 & 0.116742355 \\
& B20 & 0.035169666 & 0.007818406 \\
\hline
\end{tabular}

The individual sensitivities are shown in Table 14. As can be seen from the table, for August with the best performance, the most sensitive indicator is the clearing price, while the relatively insensitive indicator is the ratio of electricity supply and demand declared by the market. For the worst performance in July, the most sensitive indicator is the electricity declared by power generation companies, while the relatively insensitive indicator is the surplus supply rate. Therefore, the sensitivity indicators are slightly different for different months. Regulators should reasonably determine the key influencing factors according to the performance of each month, so as to better improve the market performance.

\section{Conclusions and Implications}

In this paper, the SCP model in the theory of industrial organization is used to establish the monitoring index system of power market. Fuzzy-AHP and Fuzzy-Delphi are used to calculate the weight of index, and BP-neural network is used to construct the evaluation model. In the empirical analysis, select a province five months of data, the construction and calculation of the power market monitoring index system, single factor evaluation of the relevant indicators, at the same time, the comprehensive evaluation, the operation of the power market in the selected period, and the corresponding sensitivity analysis. The research content and corresponding work of this paper are as follows:

As for the constructed index system, we get the final index system and the corresponding weight by fuzzy-Delphi and fuzzy-AHP. Calculated by the weight, in the experts' subjective intention, accounted for the most important indicators for clearing price, influence extent relatively small indicator for the market, according to the power supply and demand than reason for monitoring the overall market operation, need to focus on the clearing price impact index, prevent its fluctuations affect the whole market order.

On the basis of constructing the index system, we get the market operation monitoring situation of the five months to be evaluated through BP neural network algorithm. Of the five months assessed, August was the best and July was the worst. Therefore, for the market regulator, it is necessary to focus on analyzing the situation of these two months in order to better sum up the experience.

On the basis of the evaluation model, we carry out sensitivity analysis for individual indicators. By selecting the two months with the best performance and the relatively poor performance, the sensitivity of single index was analyzed on the basis of changing the model parameters. It can be concluded that the sensitivity indicators in the two months are slightly different. Therefore, for the regulator, specific analysis of different months is required when monitoring the operation of the electricity market, so that improvement and improvement can be made in specific months, which is conducive to the development of the overall market.

For the follow-up research of this paper, the main directions are as follows:

1. In view of the dynamic nature of power market operation monitoring, this paper will continue to build an indicator system reflecting time persistence in the follow-up work, so as to better reflect the dynamic nature of time in the indicator system;

2. In terms of the estimation of index weight, this paper 
hopes to collect more objective data in the future, so as to make a more reasonable estimate of the weight and reduce the subjectivity in the evaluation process.

3. In terms of the application of neural network, this paper hopes that a large number of objective data collected in the future work can be used for more accurate training of the network, so as to ensure the authenticity and effectiveness of training results and the authenticity of evaluation results.

\section{References}

[1] Hu, C.; Du, S.; Su, J.; Tong, G.; Wang, M. Preliminary Research of Trading Approach and Management Modes of Chinese Electricity Retail Companies Under New Electricity Market Reform. Power Syst. Technol. 2016, 40, 3293-3299.

[2] Lai, F.; Xia, Q. Electricity Characteristics and Electricity Market. Autom. Electr. Power Syst. 2005, 29, 1-5, doi: 10.3321/j.issn:1000-1026.2005.22.001.

[3] Yan, L. Research on the Electricity Regulatory System Reform in China under the Theory of Regulation. Doctor thesis, Nanjing University, 2015.

[4] Miao, Y.; Luo, W.; Lei, W.; Zhang, P.; Jiang, R.; Deng, X. Power Supply Reliability Indices Computation with Consideration of Generation Systems, Transmission Systems and Sub-Transmission Systems' Load Transfer Capabilities. In Proceedings of the 2016 IEEE PES Asia-Pacific Power and Energy Engineering Conference (APPEEC); IEEE: Xi'an, China, October 2016; pp. 1840-1844.

[5] Salarvand, A.; Mirzaeian, B.; Moallem, M. Obtaining a Quantitative Index for Power Quality Evaluation in Competitive Electricity Market. IET Gener. Transm. Distrib. 2010, 4, 810, doi: 10.1049/iet-gtd.2009.0479.

[6] Tianrui Zhou; Qixin Chen; Wentao Zhu; Li Zhang; Chongqing Kang A Comprehensive Low-Carbon Benefits Assessment Model for Power Systems. In Proceedings of the 2012 IEEE International Conference on Power System Technology (POWERCON); IEEE: Auckland, October 2012; pp. 1-5.

[7] Song, M.; Cui, L.-B. Economic Evaluation of Chinese Electricity Price Marketization Based on Dynamic Computational General Equilibrium Model. Comput. Ind. Eng. 2016, 101, 614-628, doi: 10.1016/j.cie.2016.05.035.

[8] Lee, Y.-Y.; Baldick, R.; Hur, J. Firm-Based Measurements of Market Power in Transmission-Constrained Electricity Markets. IEEE Trans. Power Syst. 2011, 26, 1962-1970, doi: 10.1109/TPWRS.2011.2157179.

[9] Xie, J.; Wang, S.; Zhou, X.; Sun, B.; Sun, X. Credit Evaluation Method of Generating Companies Considering the Market Behavior in China Electricity Market. Energy Sci. Eng. 2021, 9, 1554-1567, doi: 10.1002/ese3.929.

[10] Zhao, H.; Zhao, H.; Guo, S. Comprehensive Performance Evaluation of Electricity Grid Corporations Employing a Novel MCDM Model. Sustainability 2018, 10, 2130, doi: 10.3390/su10072130.

[11] Li, X. Research on Evaluation Indexes and Methods of Electricity Market in China. Master thesis, North China Electric Power University, 2017.
[12] Li, T.; Wang, S. Research on Evaluation System of Electricity Market Transaction in China Based on Gray Relational Grade Analysis and Fuzzy Analytic Hierarchy Process. Ind. Technol. Econ. 2018, 37, 130-137.

[13] Guo, L.; Wei, F.; Xia, Q.; Zhuang, Y.; Ma, L. Discussions on Evaluation Index Framework of Power Market in China. Electr. POWER Technol. Econ. 2008, 29-34.

[14] Xiao, L. Research on the Current Status of the Cultural Industry Organization in China and Development Countermeasures. In Proceedings of 2015 2nd International Conference on Industrial Economics System and Industrial Security Engineering; Li, M., Zhang, Q., Zhang, J., Li, Y., Eds.; Springer Singapore: Singapore, 2016; pp. 247-253 ISBN 978-981-287-654-6.

[15] Kening, C.; Qu, H.; Ma, Q.; Luo, Z.; Wenjun, Z. Design of China's Electricity Market Evaluation Indicators Based on SCP Model. IOP Conf. Ser. Earth Environ. Sci. 2021, 657, 012092, doi: 10.1088/1755-1315/657/1/012092.

[16] Qi, S.; Wang, X.; Zhang, W.; Wu, X.; Wang, G.; Shi, X.; Wang, Y. Evaluation Index System for Clearing Models of Different Electricity Price Policies. In Proceedings of the 2018 2nd IEEE Conference on Energy Internet and Energy System Integration (EI2); IEEE: Beijing, China, October 2018; pp. 1-6.

[17] Chang, P.-T.; Huang, L.-C.; Lin, H.-J. The Fuzzy Delphi Method via Fuzzy Statistics and Membership Function Fitting and an Application to the Human Resources. Fuzzy Sets Syst. 2000, 112, 511-520, doi: 10.1016/S0165-0114(98)00067-0.

[18] Li, Y. Analysis and Improvement Applications Of BP Neutral Network. Master thesis, Anhui University of Science and Technology, 2012.

[19] Li, J. Research on Marketing Performance Evaluation of Urban Complex Based on AHP and BP Neural Network. Microcomput. Appl. 2021, 37, 158-162.

[20] Gao, X. Research on the Efficiency of the Listed Electric Power Enterprises in China Based on DEA Method. Master thesis, East China University of Political Science and Law, 2013.

[21] Wang, J.; Ding, D.; Liu, O.; Li, M. A Synthetic Method for Knowledge Management Performance Evaluation Based on Triangular Fuzzy Number and Group Support Systems. Appl. Soft Comput. 2016, 39, 11-20, doi: 10.1016/j.asoc.2015.09.041.

[22] Tseng, M.-L. Using Hybrid MCDM to Evaluate the Service Quality Expectation in Linguistic Preference. Appl. Soft Comput. 2011, 11, 4551-4562, doi: 10.1016/j.asoc.2011.08.011.

[23] Ebrahimi, S.; Bridgelall, R. A Fuzzy Delphi Analytic Hierarchy Model to Rank Factors Influencing Public Transit Mode Choice: A Case Study. Res. Transp. Bus. Manag. 2021, 39, 100496, doi: 10.1016/j.rtbm.2020.100496.

[24] Ilbahar, E.; Kahraman, C.; Cebi, S. Risk Assessment of Renewable Energy Investments: A Modified Failure Mode and Effect Analysis Based on Prospect Theory and Intuitionistic Fuzzy AHP. Energy 2022, 239, 121907, doi: 10.1016/j.energy.2021.121907.

[25] James, A. T.; Vaidya, D.; Sodawala, M.; Verma, S. Selection of Bus Chassis for Large Fleet Operators in India: An AHP-TOPSIS Approach. Expert Syst. Appl. 2021, 186, 115760, doi: 10.1016/j.eswa.2021.115760. 
[26] Gogus, O.; Boucher, T. O. Strong Transitivity, Rationality and Weak Monotonicity in Fuzzy Pairwise Comparisons. Fuzzy Sets Syst. 1998, 94, 133-144, doi: 10.1016/S0165-0114(96)00184-4.

[27] Aragonés-Beltrán, P.; Chaparro-González, F.; Pastor-Ferrando, J.-P.; Pla-Rubio, A. An AHP (Analytic Hierarchy Process)/ANP (Analytic Network Process)-Based Multi-Criteria Decision Approach for the Selection of Solar-Thermal Power Plant Investment Projects. Energy 2014, 66, 222-238, doi: 10.1016/j.energy.2013.12.016.
[28] Zhou, J. Efficiency Evaluation of Container Terminal Based on AHP and BP Neutral Network. Master thesis, Jimei University, 2020.

[29] Yang, Y.; Zheng, X.; Sun, Z. Coal Resource Security Assessment in China: A Study Using Entropy-Weight-Based TOPSIS and BP Neural Network. Sustainability 2020, 12, 2294, doi: 10.3390/su12062294. 